\title{
Flow Diverter Stents in the Treatment of Cerebral Aneurysms Less than $5 \mathrm{~mm}$
}

\author{
Erol AKGUL ${ }^{1}$, Hasan Bilen ONAN², Sabriye Sennur BILGIN ${ }^{3}$, Alican TAHTA ${ }^{4}$, Elmir KHANMAMMADOV ${ }^{5}$, \\ Fatma Zeynep GUNGOREN ${ }^{3}$, Gulhan ERTAN ${ }^{3}$, Cengiz EROL ${ }^{3}$, Zeki SEKERCI ${ }^{4}$ \\ ${ }^{1}$ Istanbul Medipol University, International School of Medicine, Department of Radiology, Istanbul, Turkey \\ ${ }^{2}$ Cukurova University, School of Medicine, Department of Radiology, Adana, Turkey \\ ${ }^{3}$ Istanbul Medipol University, International School of Medicine, Department of Radiology, Istanbul, Turkey \\ ${ }^{4}$ Istanbul Medipol University, International School of Medicine, Department of Neurosurgery, Istanbul, Turkey \\ ${ }^{5}$ Istanbul Medipol University, International School of Medicine, Department of Neurology, Istanbul, Turkey
}

This study has been presented at the $15^{\text {th }}$ Congress of the World Federation of Therapeutic and Interventional Neuroradiology between 21 and 24 October 2019 at Naples, Italy.

Corresponding author: Erol AKGUL akgulerol@gmail.com

\section{ABSTRACT}

AIM: To evaluate the safety and efficacy of flow diverter (FD) stents in the treatment of intracranial aneurysms less than $5 \mathrm{~mm}$.

MATERIAL and METHODS: We treated 66 aneurysms in 43 patients with aneurysms less than 5 mm. Of the patients, 29 were females and 14 males (mean age: 50.2 years). Headache was the most frequent symptom. In 8 patients the aneurysms were recanalized and these had been treated with coils or stent-assisted coiling. All aneurysms were in the anterior circulation. In the treatment, one of the SILK, Pipeline, Derivo or FRED FD stents was used for each patient. Neurointerventional stent medication (double antiplatelet) was used. All patients were investigated for new ischemic lesions with diffusion-weighted imaging one day later. The first follow-up angiogram was planned 3-6 months later.

RESULTS: The treatment was technically successful in all patients. Minor complications occurred in 3 patients (7\%). In one patient, thrombus inside the SILK was seen and was relieved with tirofiban. The second patient bled from the right common femoral artery entrance, which was operated on. In the third patient, the complication was technical. All patients were discharged without any neurological deficit. The mean follow-up period was 26 (6-52) months. Of the aneurysms, 64 (97.0\%) were completely closed.

CONCLUSION: The FD treatment of cerebral, anterior circulation small aneurysms less than $5 \mathrm{~mm}$ is effective and safe.

KEYWORDS: Cerebral aneurysm, Endovascular treatment, Flow diverter

ABBREVIATIONS: FD: Flow diverter, ICA: Internal carotid artery, PED: Pipeline embolization device, SAH: Subarachnoid hemorrhage, ACT: Serum-activated coagulation time, CT: Computed tomography, MCA: Middle cerebral artery, ACA: Anterior cerebral artery, ACOM: Anterior communicating artery

Erol AKGUL $\quad$ (1): 0000-0003-0020-3759

Hasan Bilen ONAN $\quad$ (D): 0000-0002-1486-2782

Sabriye Sennur BILGIN (1) : 0000-0003-1795-2596
Alican TAHTA

Elmir KHANMAMMADOV

Fatma Zeynep GUNGOREN (1) : 0000-0002-4437-9310
Gulhan ERTAN (1) : 0000-0002-0742-1305

Cengiz EROL (1) : 0000-0003-3468-7712

Zeki SEKERCI (1) : 0000-0002-6983-8632 


\section{- INTRODUCTION}

$\mathrm{B}$ ig, wide-necked, and fusiform cerebral aneurysm treatment with flow diverter (FD) stents is a milestone in interventional neuroradiology. The high rate of successful treatment, low rate of aneurysm recanalization, easy insertion, and short duration of procedure mean that FDs are preferred as the first choice of treatment. The efficacy and safety of FD treatment of these aneurysms have resulted in its widespread use for all kinds of aneurysms, including ruptured or unruptured small or blister-like ones, which are difficult to treat $(4,6,8,9,13,16,19,23,27,30)$.

We evaluated the safety and efficacy of FD stents by analyzing the procedural complications, angiographic results, and clinical outcomes in the treatment of intracranial aneurysms of less than $5 \mathrm{~mm}$ with certain indications.

\section{MATERIAL and METHODS}

In this retrospective study, we treated 66 aneurysms less than $5 \mathrm{~mm}$ in size in 43 patients. The Institutional Ethics Committee approved the study (Date: 19.02.2020; No: 191). Written and signed informed consent was obtained from each patient. Of the patients in the study, 29 were females and 14 males (mean age: 50.2 years). We treated small aneurysms in patients with headache, ophthalmoplegia, or subarachnoid hemorrhage (SAH) (in late phase), and the ruptured or unruptured aneurysms larger than $5 \mathrm{~mm}$ were surgically or endovascularly managed, but their recanalization size was less than $5 \mathrm{~mm}$. Only 8 aneurysms were incidentally detected, but they were associated with the additional larger aneurysms treated endovascularly or surgically. An internal carotid artery (ICA) cavernous small aneurysm associated with other parophthalmic aneurysms was treated. Headache was the most frequent symptom. In 8 patients, the aneurysms were recanalized, and these had been treated with coils only (4 aneurysms) or stent-assisted coiling (4 aneurysms). In one patient with $\mathrm{SAH}$, the ophthalmic aneurysm was treated with Derivo one month after hemorrhage. All aneurysms were in the anterior circulation. Of 66 aneurysms, 6 were beyond the ICA bifurcation. In the treatment, only one of the brands [SILK, Balt, Montmorency, France; Pipeline Embolization Device (PED), Medtronic Covidien AG, Paris, France; Derivo, Acandis, Pforzheim, Germany; Surpass, Stryker Neuroendovascular, Kalamazoo, MI, USA; or FRED, Microvention Terumo, Tustin, CA, USA] was used for each patient. Table I reveals the demographic and clinical data of the study population.

\section{Endovascular Technique}

After general anesthesia, access to the ICA was gained using neurovascular long introducers and distal accessguiding catheters. Before insertion of the FD, if coiling was planned, embolization was performed via a microcatheter with or without use of an aneurysm neck-remodeling balloon. A microcatheter, which is suitable to deploy the chosen FD, was inserted in the parent artery using a 0.014 or 0.016 micro guidewire, the distal end of the microcatheter passing the aneurysm neck by about 2 or $3 \mathrm{~cm}$. Then the FD was deployed to cover the neck of the aneurysm. Correct expansion of the
FD was detected under fluoroscopy, and a remodeling balloon was applied to provide proper apposition of the stent to the vessel wall in case of improper apposition. Table II shows the procedural data.

Table I: Patient Data and Aneurysm Characteristics

\begin{tabular}{lc}
\hline Value & $\mathbf{n}(\%)$ \\
\hline Total number of patients & $43(100)$ \\
\hline Sex & $29(67.4)$ \\
\hline Male & $14(32.6)$ \\
\hline Age (years) & Mean (min-max) \\
\hline Presentation & $50.2(25-73)$ \\
\hline symptomatic small aneurysms & $\mathbf{n}(\%)$ \\
\hline other treated bigger aneurysms & $14(32.6)$ \\
\hline recanalization & $20(46.5)$ \\
\hline recanalization and small aneurysms & $1(2.3)$ \\
\hline
\end{tabular}

\section{Symptoms}

\begin{tabular}{|c|c|}
\hline Headache & $24(55.8)$ \\
\hline $\begin{array}{l}\text { Incidental (associated with bigger } \\
\text { aneurysms) }\end{array}$ & $8(18.6)$ \\
\hline Recanalization during follow-up & $8(18.6)$ \\
\hline Neurologic deficit & $2(4.7)$ \\
\hline $\mathrm{SAH}$ & $1(2.3)$ \\
\hline Total aneurysms treated & 66 \\
\hline \multicolumn{2}{|l|}{ Patients' aneurysm number } \\
\hline 1 & $25(58.2)$ \\
\hline 2 & $13(30.2)$ \\
\hline 3 & $4(9.3)$ \\
\hline 4 & $1(2.3)$ \\
\hline \multicolumn{2}{|l|}{ Aneurysm location } \\
\hline MCA & $4(6.1)$ \\
\hline ACA & $1(1.5)$ \\
\hline ACOM & $1(1.5)$ \\
\hline ICA terminal & $27(40.9)$ \\
\hline ICA ophthalmic & $30(45.5)$ \\
\hline ICA cavernous & $3(4.5)$ \\
\hline
\end{tabular}

SAH: Subarachnoid hemorrhage, MCA: Middle cerebral artery, ACA: Anterior cerebral artery, ACOM: Anterior communicating artery, ICA: Internal carotid artery. 
Table II: Procedural Parameters and Statistical Data

\begin{tabular}{|c|c|}
\hline Value & n (\%) \\
\hline Treated aneurysm & $66(100)$ \\
\hline Total FD used & 46 \\
\hline SILK & $24(52.2)$ \\
\hline Derivo & 9 (19.6) \\
\hline Pipeline & $7(15.2)$ \\
\hline Surpass & $4(8.7)$ \\
\hline FRED & $2(4.3)$ \\
\hline \multirow[t]{2}{*}{ Technical success } & $43(100)$ \\
\hline & Mean \\
\hline Number of FD per case & 1.1 \\
\hline Number of FD per aneurysm & 0.7 \\
\hline Follow-up duration (months) & $6-52(26)$ \\
\hline Value & n (\%) \\
\hline \multicolumn{2}{|l|}{ Closure } \\
\hline \multicolumn{2}{|l|}{ Complete } \\
\hline Incomplete & $2(3.0)$ \\
\hline Complications & $3(7.0)$ \\
\hline Technical & $1(2.3)$ \\
\hline Clinical & $2(4.6)$ \\
\hline Periprocedural (<24 hours) & 1 \\
\hline Asymptomatic ischemia & 1 \\
\hline Mild neurologic deficit & 0 \\
\hline Severe neurologic deficit & 0 \\
\hline Permanent neurological deficit & 0 \\
\hline Mortality & 0 \\
\hline
\end{tabular}

FD: Flow diverter.

\section{Medication}

Intracranial stent medication was accomplished. Double antiplatelet medicines (acetylsalicylic acid and clopidogrel) were administered 7-10 days before the treatment. In case of resistance, aspirin dosage was increased, and clopidogrel was replaced by ticlopidine, ticagrelor, or prasugrel. The aspirin was ordered to be continued indefinitely, and clopidogrel or ticlopidine was discontinued after 6 months in patients over 50 years old. If a problem arose concerning aspirin sensitivity or gastrointestinal intolerance, aspirin was discontinued, and lifetime usage of other antiplatelet medicine was ordered. If the patient was under 50 years old, the duration of the total usage of antiplatelet medicine was planned as 3-4 years.
After entering the femoral artery, $5000 \mathrm{IU}$ heparin was given intravenously, maintaining 2 or 3 times the baseline value, and the serum-activated coagulation time (ACT) was controlled. During the procedure, 1000 IU or more of heparin was administered per hour to maintain the ACT level as stable. After the procedure, 750-1000 IU/h heparin was infused for 24 hours. Low-molecular heparin (1 or $2 \times 0.4-0.6 \mathrm{ml}$ ) was given subcutaneously for $1-5$ days after IV heparin.

\section{Follow-up}

After the procedure, flat panel computed tomography $(C T)$ was done to find out any procedural hemorrhagic complications. All patients were investigated for any ischemic focus with diffusion-weighted imaging one day later. The first and second follow-up angiograms were planned for 3-6 and 9-18 months later respectively.

\section{RESULTS}

The treatment was technically successful in all patients. In 3 patients, two FDs were used. Two patients had aneurysms bilaterally, and in another patient, the FD (Surpass) caused angulation of the middle cerebral artery. This angulation was treated with a second Surpass placed distally. The most used FD was the SILK (52.2\%), and the second was the Derivo FD (19.6\%). The number of FDs per case was 1.1, and the number of FDs per aneurysm was 0.7 (Table II).

Minor complications occurred in 3 patients (7\%). In one patient, thrombus inside SILK was seen, which was relieved with tirofiban. However, some asymptomatic acute focal small ischemic lesions were seen on follow-up magnetic resonance imaging $(\mathrm{MRI})$. The second patient bled from the right common femoral artery entrance, which was operated on. In the third patient, complication was technical. The Derivo FD was stuck in the microcatheter during insertion, so a new Derivo was inserted. Hemorrhagic complication was not seen on CT performed immediately after the procedure. All patients were sent home without any neurological deficit.

The mean follow-up period was $26(6-52)$ months. Of the 66 aneurysms, 64 (97.0\%) were completely closed (Table III). In the other 2 patients, 2 aneurysms were still filling at their follow-up angiographies. One of the patients had 2 ICA ophthalmic segment small aneurysms located on the anterior and posterior wall and was treated with a SILK FD. A 48-month angiogram revealed that the anterior wall aneurysm was still filling, while the other one was completely closed. In the other patient, a recanalized aneurysm previously treated with stentassisted [Enterprise: Codman Neurovascular, Inc., Raynham, MA, USA (formerly Cordis, Johnson and Johnson Medical, Miami, FL, USA)] coiling was treated with a SILK FD device, and the aneurysm was still filling at the 18-month angiography. Figures 1A-D; 2A, B; 3A-D show a representative case.

\section{DISCUSSION}

Because the usage of FDs in the treatment of intracranial complex, wide-necked big and giant, and fusiform aneurysms has been highly effective and safe, many studies showing 

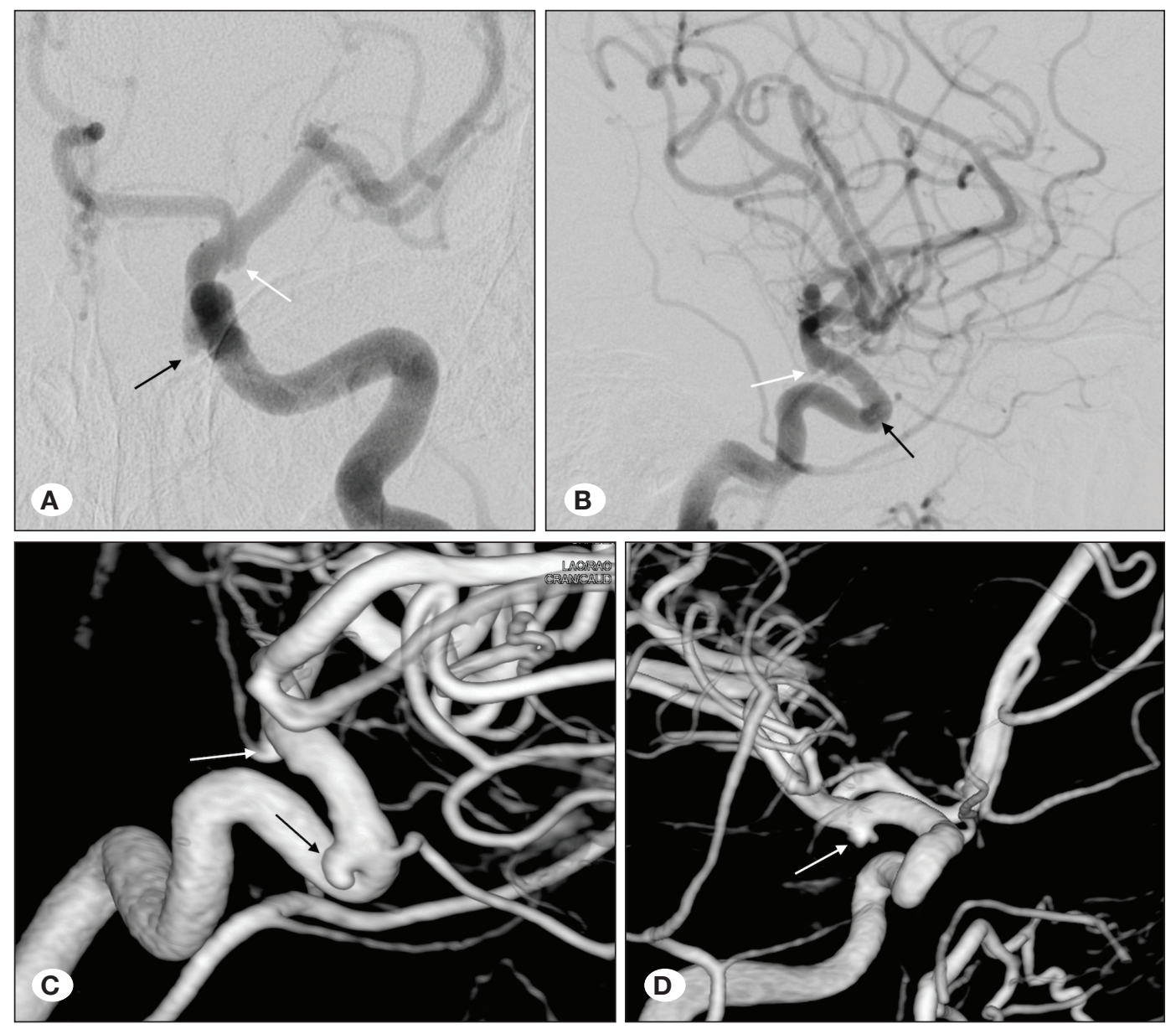

Figure 1: A 49-year-old patient suffering from headache was evaluated with digital subtraction angiography and 2 small aneurysms (A-D) of the left internal carotid artery ophthalmic segment (black arrows, A-C) and anterior choroidal artery (white arrows, A-D) were seen.
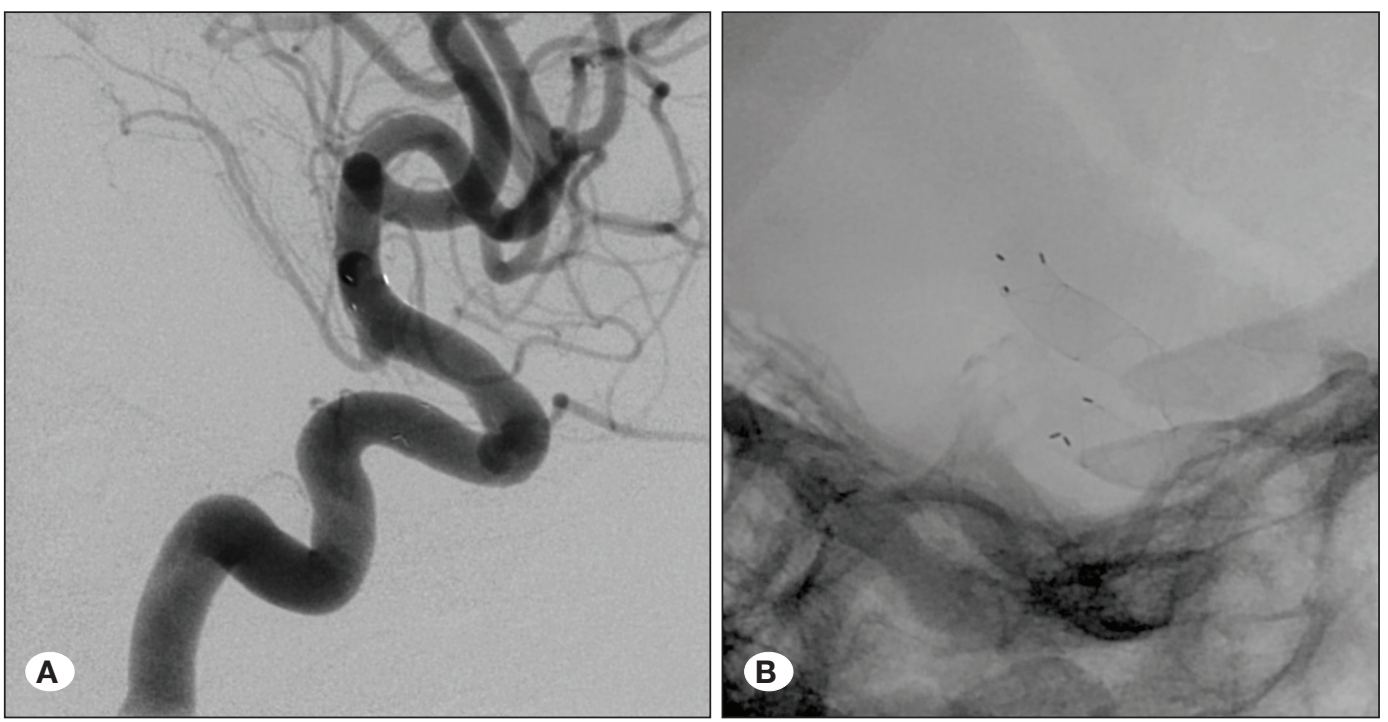

Figure 2: A Derivo flow diverter stent was implanted (A and B).

the feasibility and effectivity of the FDs in the treatment of nearly all kinds of aneurysms, ruptured or unruptured, located proximal or distal to ICA bifurcation, or either in the anterior or posterior circulation, have appeared in recent years $(6,7,10,13,17,23,24,26,27,30,31)$. Those aneurysms treated with FDs also include blister aneurysms. Surgical procedures or conventional endovascular treatment of blister aneurysms is challenging, but their treatment with FDs has provided satisfactory advancement by reducing the morbidity and mortality $(12,23,29)$. The FD technique relies on the 

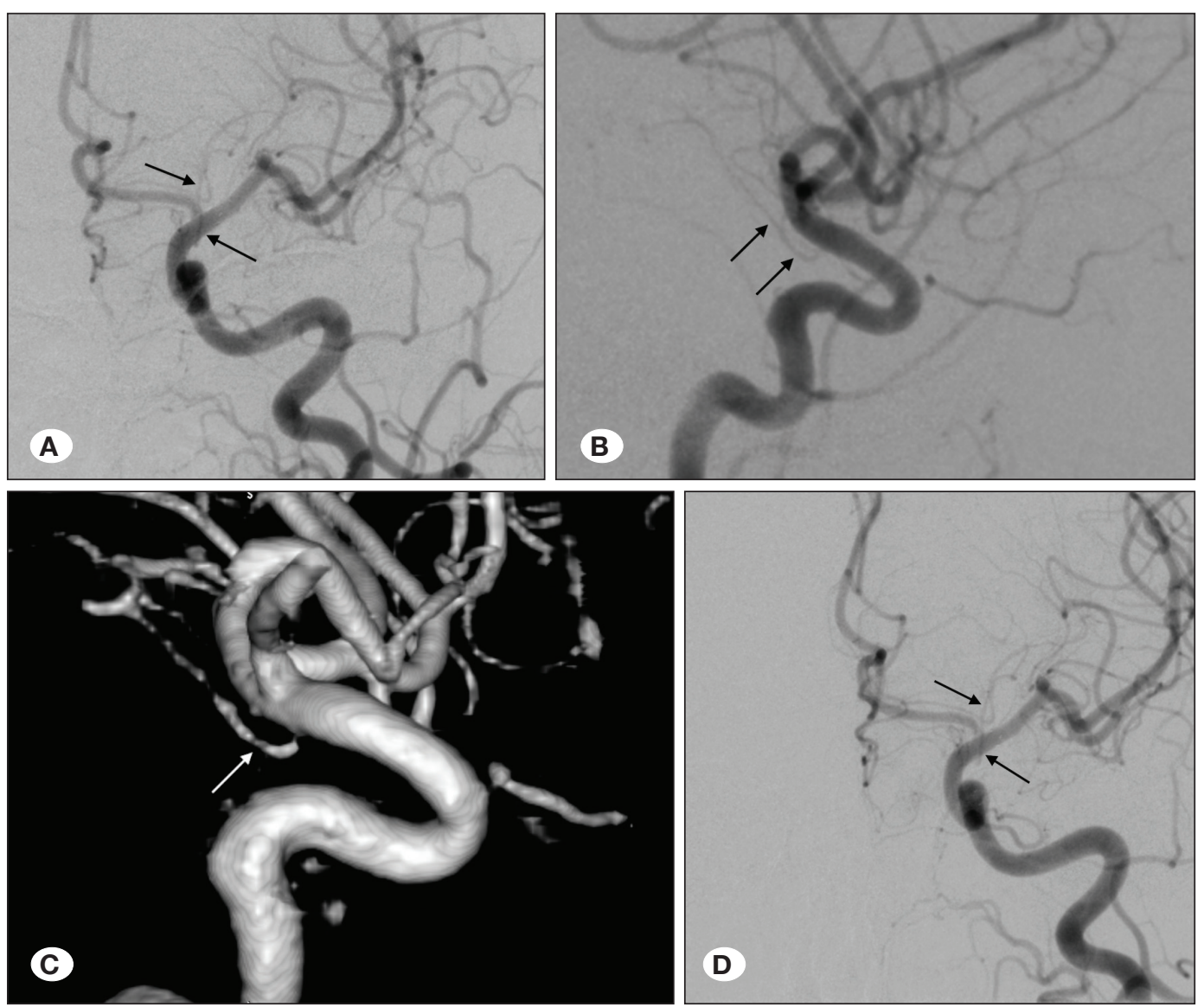

Figure 3: The 3- (A-C) and 9-month (D) angiography showed complete closure of 2 aneurysms. Although the aneurysm had disappeared, the anterior choroidal artery was still patent (black and white arrows, A-D).

endoluminal reconstruction concept of the parent artery and the exclusion of the aneurysm from the blood flow. The flow stasis inside the aneurysm causes an inflammatory reaction, followed by thrombosis and healing of the aneurysm, while the stent helps with neointimal proliferation and remodeling of the parent vessel (2).

Treatment indications of small unruptured aneurysms are not clearly defined. Although their natural course is unclear, the annual rupture risk is extremely low. However, once rupture occurs, morbimortality is extremely high. No conflict exists regarding decision-making for patients with large or small ruptured aneurysms needing to be treated, given the high risk of re-rupture within the first days and weeks $(11,22,25)$. That said, timing or indications of treatment of the unruptured small aneurysms is not defined. Burkhardt et al. (11) reviewed the current evidence for the management of unruptured small cerebral aneurysms, recommending treatment of small unruptured aneurysms in case of being symptomatic, lower treatment risk than rupture risk including an $\mathrm{SAH}$ from another ruptured aneurysm, family history (first degree), and any related genetic disease. Aneurysm features, such as anatomic location, a borderline size $(5-7 \mathrm{~mm})$, and aneurysm shape with blebs or multiple lobules, were conditions for which management was favored. The researchers considered the patients' age and decided in favor of aneurysm treatment if the patients were under 50 and in favor of clinical followup if over 70. In our study, all treated aneurysms caused symptoms or were associated with other aneurysms that were endovascularly or surgically treated or were recanalized after clipping or embolization. The symptoms of the patients in our study were headache, ophthalmoplegia, and SAH (treated in late phase). Only 8 aneurysms were incidentally detected, but they were associated with the additional larger aneurysms treated endovascularly or surgically. Of 3 patients over 70 years old, only 2 had symptoms: One had speaking disturbance, and the other had headache and 2 aneurysms of the ICA ophthalmic and cavernous segment. The third patient was treated for unruptured middle cerebral artery bifurcation aneurysm with Y-stenting technique and had a $5 \mathrm{~mm}$ small unruptured aneurysm.

The optimal management of these small aneurysms remains uncertain despite the appearance of the new less invasive endovascular and microsurgical treatment techniques. Coiling with or without a device-assisted technique in the management of these small aneurysms was the preferred technique before FD devices. The rates of leaving remnant and recanalization are high in these aneurysms' treatment. Periprocedural complications are also not inconsiderable $(3,20,25,32)$. Oishi et al. reported that 481 small $(<10 \mathrm{~mm})$ asymptomatic and unruptured aneurysms were treated with or 
without balloon-assisted coiling. In their study, the immediate complete occlusion rate was $64.2 \%$. Procedure-related complications were seen in 38 patients $(7.6 \%)$, but permanent morbidity $(0.8 \%)$ and mortality $(0.2 \%)$ were extremely low. In contrast, the recanalization rate was high in 427 aneurysms for which a conventional or MR angiographic follow-up was performed at $>6$ months $(n=72,16.9 \%)$. Retreatment was performed in $9.9 \%$ of aneurysms. The authors concluded that even though the role of endovascular treatment as a prophylactic therapy remained controversial, endovascular treatment of small asymptomatic unruptured aneurysms was highly effective and safe with low morbimortality rates (25). In Loumiotis et al's study including 65 patients with 69 small aneurysms $(<10 \mathrm{~mm})$, treated with only coiling, balloon-, or stent-assisted coiling, FD (only in one), or only stent (only in one), the immediate occlusion rate was $25.6 \%$ and the final occlusion rate was $48.8 \%$. A periprocedural complication was seen in 6 patients (9.2\%), permanent morbidity in one, and mortality in another patient. A late complication that resulted in a permanent neurologic deficit was seen in one patient (20). In their meta-analysis, Yamaki et al. analyzed 22 studies with 1105 small $(\leq 3 \mathrm{~mm}$ ) aneurysms, including 844 ruptured and 261 unruptured endovascularly treated ones. Postprocedural and long-term complete occlusion were obtained in $85 \%$ and $91 \%$ of these aneurysms, respectively. The rate of recanalization was $6 \%$, and retreatment was conducted in $7 \%$ of cases. Seventy-nine percent of patients' neurologic outcome was good at long-term follow-up. Rupture during the procedure occurred in $7 \%$ of the embolizations, while embolic complications were seen in $4 \%$. The researchers concluded that extremely small cerebral aneurysm embolization with coil could be safe and effective. Procedure-related complications were considerable in the unruptured aneurysms (32).

In recent reports, treatment of small aneurysms with FDs has been shown to be feasible and effective $(8,9,13,14,33)$. However, experience remains limited. Lin et al. (19) treated 53 ICA aneurysms smaller than $10 \mathrm{~mm}$ with PED in 41 patients. PED was successfully placed in 42 of 44 treatments $(95.5 \%)$. Though major complications were seen in one patient $(2.3 \%)$, who died due to early $\mathrm{SAH}$, minor complications occurred in 3 patients (6.9\%). These were transient neurological deficits, late asymptomatic intracerebral hemorrhage, and delayed groin infection. Complete or near-complete aneurysm occlusion at 6-month follow-up angiography was seen in $80 \%$. The number of PEDs implanted per treatment was 1.1. One PED was implanted in $37(88.1 \%)$ treatments, and 2 PEDs were implanted in $5(11.9 \%)$ treatments. In their meta-analysis, Yao et al. analyzed 10 observational studies. The rate of complete aneurysm occlusion was $84.23 \%$. The mortality and morbidity rates, including intracerebral hemorrhage, ischemia, and $\mathrm{SAH}$, were $0.87 \%$ and $5.22 \%$, respectively. The permanent morbidity (procedure-related) was $2.41 \%$ (33). In their study including 104 patients, Pumar et al. assessed retrospectively the safety and efficacy of the SILK FD in the treatment of 109 small unruptured cerebral aneurysms less than $10 \mathrm{~mm}$. A total of 44 patients were symptomatic (42.3\%), and 102 aneurysms $(93.6 \%)$ were in the anterior circulation. At 6 months, the neurologic morbidity and mortality rates were $2.9 \%$ and $0.9 \%$, respectively. The 12 -month follow-up imaging revealed complete occlusion, residual neck, and residual aneurysm in $88.5 \%, 7.7 \%$, and $3.3 \%$ of 78 cases, respectively (27).

In our study group, 64 of the 66 aneurysms (97.0\%) were completely closed during the mean follow-up period of 26 (6-52) months. Minor complications, one technical and two clinical, were seen in 3 patients (7\%) without any permanent neurologic defisicits. No mortality was seen. Amongst our patients, only one patient's aneurysm was ruptured, and this aneurysm was treated one month later, not in the acute phase. Thus, we can assume that all aneurysms in our study were unruptured during treatment.

Another indication of the aneurysm treatment with FD is the remnant or recanalization of the aneurysms previously clipped or endovascularly treated with other techniques beyond FD $(1,5,15,18,21,28)$. Schwartz et al. treated 6 patients with recurrent aneurysms that were previously clipped and encountered no periprocedural morbidity or mortality. They concluded that endovascular treatment with FD in those patients was a feasible treatment with low risk and might prevent the risks of resurgery (28). Daou et al., Kühn et al. and Bender et al. treated recurrent or remnant aneurysms after surgical clipping or endovascular treatment with Pipeline FD and reported that the management of these aneurysms with FD is feasible, safe, and effective $(5,15,18)$. In our study, there were 8 recanalized aneurysms less than $5 \mathrm{~mm}$ in 8 patients. Of these aneurysms, 4 had been treated with stent-assisted coiling. A patient with ICA ophthalmic segment aneurysm treated with an Enterprise stent and coil displayed recanalization. This aneurysm, treated with SILK FD, was still filling at the 18-month follow-up angiography. However, other recanalized aneurysms treated with coiling or stent-assisted coiling were completely closed during the follow-up.

\section{Study Limitations}

Our study has some limitations: It is retrospective, and there is no control group. Even though the patients' symptoms and treatment indications were inhomogeneous, all aneurysms were considered together. Additionally, FD stents used in the treatment were of different brands. That said, it should not be forgotten that all FDs used in cerebral aneurysm treatment have been reported to have similar efficacy and safety in the literature $(2,9,13,27)$.

\section{CONCLUSION}

FD stents are effective and safe in the treatment of intracranial, anterior circulation small aneurysms less than $5 \mathrm{~mm}$ in size. The treatments of these aneurysms have high complete occlusion rates, and the complication rates are low. The FD indications for small intracranial aneurysm treatment can be extended. Even though there are many benefits of treating small symptomatic or asymptomatic incidental or recanalized intracranial aneurysms, in some incidences, there may be risks in the treatment of such aneurysms. This can be clarified through some long-term randomized clinical trials. 


\section{REFERENCES}

1. Adeeb N, Griessenauer CJ, Moore J, Stapleton CJ, Patel AB, Gupta R, Patel AS, Thomas AJ, Ogilvy CS: Pipeline embolization device for recurrent cerebral aneurysms after microsurgical clipping. World Neurosurg 93:341-345, 2016

2. Akgul E, Onan HB, Akpinar S, Balli HT, Aksungur EH: The DERIVO embolization device in the treatment of intracranial aneurysms: Short- and midterm results. World Neurosurg 95:229-240, 2016

3. Anokwute MC, Braca JA, Bohnstedt B, DeNardo A, Scott J, Cohen-Gadol A, Sahlein DH: Endovascular treatment of ruptured tiny $(3 \mathrm{~mm})$ intracranial aneurysms in the setting of subarachnoid hemorrhage: A case series of 20 patients and literature review. J Clin Neurosci 40:52-56, 2017

4. Awad AJ, Mascitelli JR, Haroun RR, Leacy RA De, Fifi JT, Mocco J: Endovascular management of fusiform aneurysms in the posterior circulation: The era of flow diversion. Neurosurg Focus 42(6):E14, 2017

5. Bender MT, Vo CD, Jiang B, Campos JK, Zarrin DA, Xu R, Westbroek EM, Caplan JM, Huang J, Tamargo RJ, Lin LM, Colby GP, Coon AL: Pipeline embolization for salvage treatment of previously stented residual and recurrent cerebral aneurysms. Interv Neurol 7:359-369, 2018

6. Bhogal P, Chudyk J, Bleise C, Lylyk I, Perez N, Henkes H, Lylyk $P$ : The use of flow diversion in vessels $\leq 2.5 \mathrm{~mm}$ in diameter-a single-center experience. World Neurosurg 118:e575-e583, 2018

7. Bhogal $P$, Moreno RM, Ganslandt $\mathrm{O}$, Bäzner $\mathrm{H}$, Henkes $\mathrm{H}$, Perez MA: Use of flow diverters in the treatment of unruptured saccular aneurysms of the anterior cerebral artery. J Neurointerv Surg 9(3):283-289, 2017

8. Blanco-Ulla M, Dieguez B, Masso J, Mosqueira A, SoutoBayarri M, Miralbes S, Cuellar H, Vazquez-Herrero F, Pumar JM, Guimaraens L: Expanding the use of flow diverters beyond their initial indication: Treatment of small unruptured aneurysms. J Neurointerv Surg 10:245-248, 2017

9. Brinjikji W, Murad MH, Lanzino G: Endovascular treatment of intracranial aneurysms with flow diverters. Stroke 44:442-447, 2015

10. Brouillard AM, Sun X, Siddiqui AH, Lin N: The use of flow diversion for the treatment of intracranial aneurysms: Expansion of indications. Cureus 8:1-8, 2016

11. Burkhardt JK, Benet A, Lawton MT: Management of small incidental intracranial aneurysms. Neurosurg Clin N Am 28: 389-396, 2017

12. Causin F, Pascarella R, Pavesi G, Marasco R, Zambon G: Acute endovascular treatment ( $<48$ hours) of uncoilable ruptured aneurysms at non-branching sites using silk flowdiverting devices. Interv Neuroradiol 17(3):357-364, 2011

13. Chalouhi N, Starke RM, Yang S, Bovenzi CD, Tjoumakaris S, Hasan D, Gonzalez LF, Rosenwasser R, Jabbour P: Extending the indications of flow diversion to small, unruptured, saccular aneurysms of the anterior circulation. Stroke 45:54-58, 2014

14. Chalouhi N, Zanaty M, Whiting A, Yang S, Tjoumakaris S, Hasan D, Starke RM, Hann S, Hammer C, Kung D, Rosenwasser R, Jabbour P: Safety and efficacy of the Pipeline Embolization Device in 100 small intracranial aneurysms. J Neurosurg 122(6):1498-1502, 2015
15. Daou B, Starke RM, Chalouhi N, Tjoumakaris S, Khoury J, Hasan D, Rosenwasser RH, Jabbour PM: The use of the pipeline embolization device in the management of recurrent previously coiled cerebral aneurysms. Neurosurgery 77:692697, 2015

16. Karsy M, Guan J, Brock AA, Amin A, Park MS, Park MS: Emerging technologies in flow diverters and stents for cerebrovascular diseases. Curr Neurol Neurosci Rep 17:96, 2017

17. Kulcsár Z, Wetzel SG, Augsburger L, Rüfenacht DA: Effect of flow diversion treatment on very small ruptured aneurysms. Neurosurgery 67(3):789-793, 2010

18. Kühn AL, De Macedo Rodrigues K, Lozano JD, Rex DE, Massari F, Tamura T, Howk M, Brooks C, L'Heureux J, Gounis MJ, Wakhloo AK, Puri AS: Use of the Pipeline embolization device for recurrent and residual cerebral aneurysms: A safety and efficacy analysis with short-term follow-up. J Neurointerv Surg 9:1208-1213, 2017

19. Lin LM, Geoffrey P, Kim JE, Huang J, Tamargo RJ, Coon AL: Immediate and follow - up results for 44 consecutive cases of small $(<10 \mathrm{~mm})$ internal carotid artery aneurysms treated with the pipeline embolization device. Surg Neurol Int 4:114, 2013

20. Loumiotis I, Robert RDJ, Vine R, Cloft HJ, Kallmes DF, Lanzino G: Small $(<10-\mathrm{mm})$ incidentally found intracranial aneurysms, Part 2: Treatment recommendations, natural history, complications, and short-term outcome in 212 consecutive patients. Neurosurg Focus 31:1-7, 2011

21. Mai JC, Hoh BL: Endovascular management of recurrent aneurysms. Neurol Res 36:323-331, 2014

22. Malhotra A, Wu X, Forman HP, Nardini HKG, Matouk CC, Gandhi D, Moore C, Sanelli P: Growth and rupture risk of small unruptured intracranial aneurysms a systematic review. Ann Intern Med 167:26-33, 2017

23. Meling TR: What are the treatment options for blister-like aneurysms? Neurosurg Rev 40:587-593, 2017

24. Möhlenbruch MA, Kizilkilic O, Killer-Oberpfalzer M, Baltacioglu F, Islak C, Bendszus M, Cekirge S, Saatci I, Kocer N: Multicenter experience with FRED Jr flow re-direction endoluminal device for intracranial aneurysms in small arteries. AJNR Am J Neuroradiol 38(10):1959-1965, 2017

25. Oishi $H$, Yamamoto $M$, Shimizu T, Yoshida $K$, Arai $H$ : Endovascular therapy of 500 small asymptomatic unruptured intracranial aneurysms. Am J Neuroradiol 33:958-964, 2012

26. Peschillo S, Caporlingua A, Resta MC, Paul Peluso JP, Burdi N, Sourour N, Diana F, Guidetti G, Clarençon F, Bloemsma GC, Maria F Di, Donatelli M, Resta M: Endovascular treatment of large and giant carotid aneurysms with flow-diverter stents alone or in combination with coils: A multicenter experience and long-term follow-up. Oper Neurosurg 13:492-502, 2017

27. Pumar JM, Mosqueira A, Cuellar H, Dieguez B, Guimaraens $\mathrm{L}$, Masso J, Miralbes S: Expanding the use of $\mathrm{fl}$ ow diverters beyond their initial indication: Treatment of small unruptured aneurysms. J Neurolntervent Surg 10:245-248, 2018

28. Romagna A, Ladisich B, Schwartz C, Winkler PA, Rahman AS: Flow-diverter stents in the endovascular treatment of remnants in previously clipped ruptured aneurysms: A feasibility study. Interv Neuroradiol 25(2):159101991880577, 2018 
29. Strickland BA, Rennert RC, Bakhsheshian J, Ravina K, Fredrickson V, Giannotta SL, Russin JJ: Extracranialintracranial bypass for treatment of blister aneurysms: Efficacy and analysis of complications compared with alternative treatment strategies. World Neurosurg 117:e417-e424, 2018

30. Tjoumakaris S, Yang S, Rosenwasser R, Hasan D, Chalouhi N, Jabbour P, Starke RM, Gonzalez LF, Bovenzi CD: Extending the indications of flow diversion to small, unruptured, saccular aneurysms of the anterior circulation. Stroke 45:54-58, 2013
31. Topcuoglu OM, Akgul E, Daglioglu E, Topcuoglu ED, Peker A, Akmangit I, Belen D, Arat A: Flow diversion in middle cerebral artery aneurysms: Is it really an all-purpose treatment? World Neurosurg 87:317-327, 2016

32. Yamaki VN, Brinjikji W, Murad MH, Lanzino G: Endovascular treatment of very small intracranial aneurysms: Meta-analysis. Am J Neuroradiol 37:862-867, 2016

33. Yao X, Ma J, Li H, Shen H, Lu X, Chen G: Safety and efficiency of flow diverters for treating small intracranial aneurysms: A systematic review and meta-analysis. J Int Med Res 45:1121,2017 